Stochastic formation of fibrillar and amorphous superoxide dismutase oligomers linked to amyotrophic lateral sclerosis.

Alireza Abdolvahabi ${ }^{\mathrm{a}}$, Yunhua Shi ${ }^{\mathrm{a}}$, Aleksandra Chuprin ${ }^{\mathrm{a}}$, Sanaz Rasouli ${ }^{\mathrm{a}, \mathrm{b}}$, Bryan F. Shaw $^{\mathrm{a}^{*}}$

${ }^{\mathrm{a} D e p a r t m e n t ~ o f ~ C h e m i s t r y ~ a n d ~ B i o c h e m i s t r y, ~ B a y l o r ~ U n i v e r s i t y, ~ W a c o, ~ T X ~ 76798-7348 ~}$

${ }^{\mathrm{b}}$ Institute of Biomedical Studies, Baylor University, Waco, TX 76798-7348

*Corresponding Author: Bryan_Shaw@baylor.edu

***Supporting Information*** 


\section{Supporting Methods:}

\section{Thioflavin-T (ThT) and 1-anilino-8-naphthalene sulfonate (ANS) fluorescence aggregation}

assays: The aggregation of WT and ALS-variant apo-SOD1 proteins into amyloid was monitored using high-throughput ThT fluorescence assays in a 96-well black polystyrene plate (measured with a Thermo Scientific Fluoroskan Ascent 2.5 Fluorescence spectrophotometer), and data were analyzed as previously described. ${ }^{1}$ Assays were carried out at a protein concentration of $60 \mu \mathrm{M}$ (per monomer), $20 \mu \mathrm{M}$ ThT, $0 \mathrm{mM}$ or $150 \mathrm{mM} \mathrm{NaCl}, 10 \mathrm{mM}$ potassium phosphate, $\mathrm{pH} 7.4,37^{\circ} \mathrm{C}, 10 \mathrm{mM}$ or $100 \mathrm{mM}$ TCEP, and $5 \mathrm{mM}$ EDTA. Excitation and emission wavelength pairs were $444 \mathrm{~nm} / 485 \mathrm{~nm}$ for ThT and $350 \mathrm{~nm} / 500 \mathrm{~nm}$ for ANS. A $3.18 \mathrm{~mm}$ Teflon bead was added to each well of the microplate (maximum of 60 wells out of 96 , since we did not use outside wells which sometimes form faulty seals with polypropylene sheets). The plate was carefully sealed with a pre-warmed polypropylene seal. We note that the calculated diffusion of $\mathrm{O}_{2}$ through the polypropylene seal at $37{ }^{\circ} \mathrm{C}$ will occur at $\approx 4.3 \times 10^{-7} \mathrm{mg} / \mathrm{hr}$ which can theoretically oxidize only $0.4 \mathrm{nmol}$ of TCEP-out of $2000 \mathrm{nmol}$ present $(0.02 \%)$-during the 168 hr assay in each well. Fibrillization was initiated by automated gyration of the microplate at 360 rpm. This gyration does not occur throughout the entire ThT assay, but occurs in bursts of $15 \mathrm{sec}$, followed by a pause of $15 \mathrm{sec}$; the radius of gyration is $3 \mathrm{~mm}$. Fluorescence was measured every $15 \mathrm{~min}$, for $168 \mathrm{hr}$. In order to determine how reaction conditions affected the stochastic nature (and rate) of amyloid formation, reaction conditions were varied (i.e., temperature, protein concentration, ionic strength, and speed of plate gyration).

Prior to initiating the ThT kinetic assays, all apo-SOD1 solutions were filtered with a 0.2 $\mu \mathrm{m}$ filter (to remove pre-formed oligomers that can seed aggregation), and pipetted into different wells of a 96-well plate. The absence of any residuals of soluble protein at the end of aggregation 
assays was confirmed with SDS-PAGE on the supernatant of centrifuged fibril homogenates, as previously described. ${ }^{1}$ The gross morphology of formed aggregates was determined with transmission electron microscopy, as previously described. ${ }^{1}$

All sets of ThT and ANS kinetic data were fit with a 4-parameter sigmoidal function (Equation S1):

$$
f=f_{0}+\frac{f_{\max }}{1+e^{\frac{t-t_{0}}{b}}}
$$

Where $f$ is ThT emission intensity at $485 \mathrm{~nm}, f_{0}$ and $f_{\max }$ are minimum and maximum fluorescence intensities, respectively, $t_{0}$ is the time where $f=1 / 2\left(f_{\text {max }}\right)$, and $b$ is defined as inverse propagation constant $(1 / k)$ with the unit of hr. Lag time $(\tau)$ of apo-SOD1 aggregation was calculated as $\tau=t_{0}-2 b$, and average values of $\tau$ and $b$ were determined by individually fitting replicate traces, not by a single fit to an average sigmoid, as previously described. ${ }^{1}$

Well and bead-specific aggregation assays: A 96-well plate that contained wells with outlier kinetic sigmoids was chosen and cooled down to $4{ }^{\circ} \mathrm{C}$ immediately after the termination of the assay. These wells were then emptied, beads were removed, and both were then washed with detergent, guanidinium hydrochloride $(\mathrm{GdmHCl})$, and pepsin, to remove any aggregates that were adhered to the wells. The washing protocol was as follows: wells were washed with MilliQ water with 5 volumes, and then filled with $250 \mu \mathrm{L}$ of boiling $2 \mathrm{x}$ Laemmli buffer containing $2.1 \%$ SDS. The plate was then sealed with a polypropylene sealing film and stored for $10 \mathrm{~min}$ at $50{ }^{\circ} \mathrm{C}$ with constant shaking. A similar volume of $2 \mathrm{x}$ Laemmli buffer was added to the vials containing beads and vials were boiled at $95{ }^{\circ} \mathrm{C}$ for $10 \mathrm{~min}$. All wells and beads were washed thoroughly with MilliQ water prior to incubation with $6.5 \mathrm{M} \mathrm{GdmHCl}$ and $20 \mathrm{mM}$ DTT for $12 \mathrm{hr}$ at $50{ }^{\circ} \mathrm{C}$ with gentle shaking. After $12 \mathrm{hr}$, wells and beads were washed several times 
with MilliQ water to remove all residual $\mathrm{GdmHCl}$ and DTT. Finally, in order to completely remove any remnants of small misfolded proteins or oligomers that might seed SOD1 fibrillization, $250 \mu \mathrm{L}$ of $1 \mathrm{mg} / \mathrm{mL}$ pepsin solution (100 $\left.\mathrm{mM} \mathrm{KPO}_{4}, \mathrm{pH} 2.5\right)$ was added to each well (that contained the corresponding bead) and the plate was gently shaken at $37{ }^{\circ} \mathrm{C}$ for $24 \mathrm{hr}$. Wells and beads were then washed several times with MilliQ water, dried and sealed until the initiation of a replicate aggregation assay. The new assay was performed in a similar condition as the first assay.

\section{Statistical analyses of lag time and inverse propagation rate histograms of apo-SOD1}

aggregation: The log-normal distribution functions that were used to fit the non-normal histograms were as follows:

The 3-parameter log-normal distribution:

$$
y=\frac{a}{x} \mathrm{e}^{\left[-0.5\left(\frac{\ln \left(\frac{x}{x_{0}}\right)}{b}\right)^{2}\right]}
$$

(Equation S2a)

and the 4-parameter log-normal distribution:

$$
y=y_{0}+\frac{a}{x} \mathrm{e}^{\left[-0.5\left(\frac{\ln \left(\frac{x}{x_{0}}\right)}{b}\right)^{2}\right]}
$$

(Equation S2b)

Where $x_{0}=\mu$ and $b=\sigma$ with $\mu$ and $\sigma$ are the mean and standard deviation of natural logarithm of $x$, respectively, and $a=\sigma(2 \pi)^{1 / 2}$.

A bimodal Lorentzian function was applied to non-normal bimodal histograms as follows: 
$y=y_{0}+\left(2 \frac{A}{\pi}\right)\left(\frac{W}{4\left(x-x_{0}\right)^{2}+W^{2}}\right)$

(Equation S3)

Where $A$ is the total area under the curve from the baseline and $W$ represents the peak width.

Exponential plots of ANS fluorescence were fit using Equation S4 as follows:

$f_{A N S}=\left(f_{0}\right)_{A N S}+\varphi\left(1-e^{-\delta x}\right)$

(Equation S4)

Where $f_{\text {ANS }}$ is ANS emission intensity at $500 \mathrm{~nm},\left(f_{0}\right)_{A N S}$ and $\varphi$ are minimum and maximum fluorescence intensities, respectively, and $\delta$ is the growth rate of amorphous species. 


\section{Supporting Figures:}
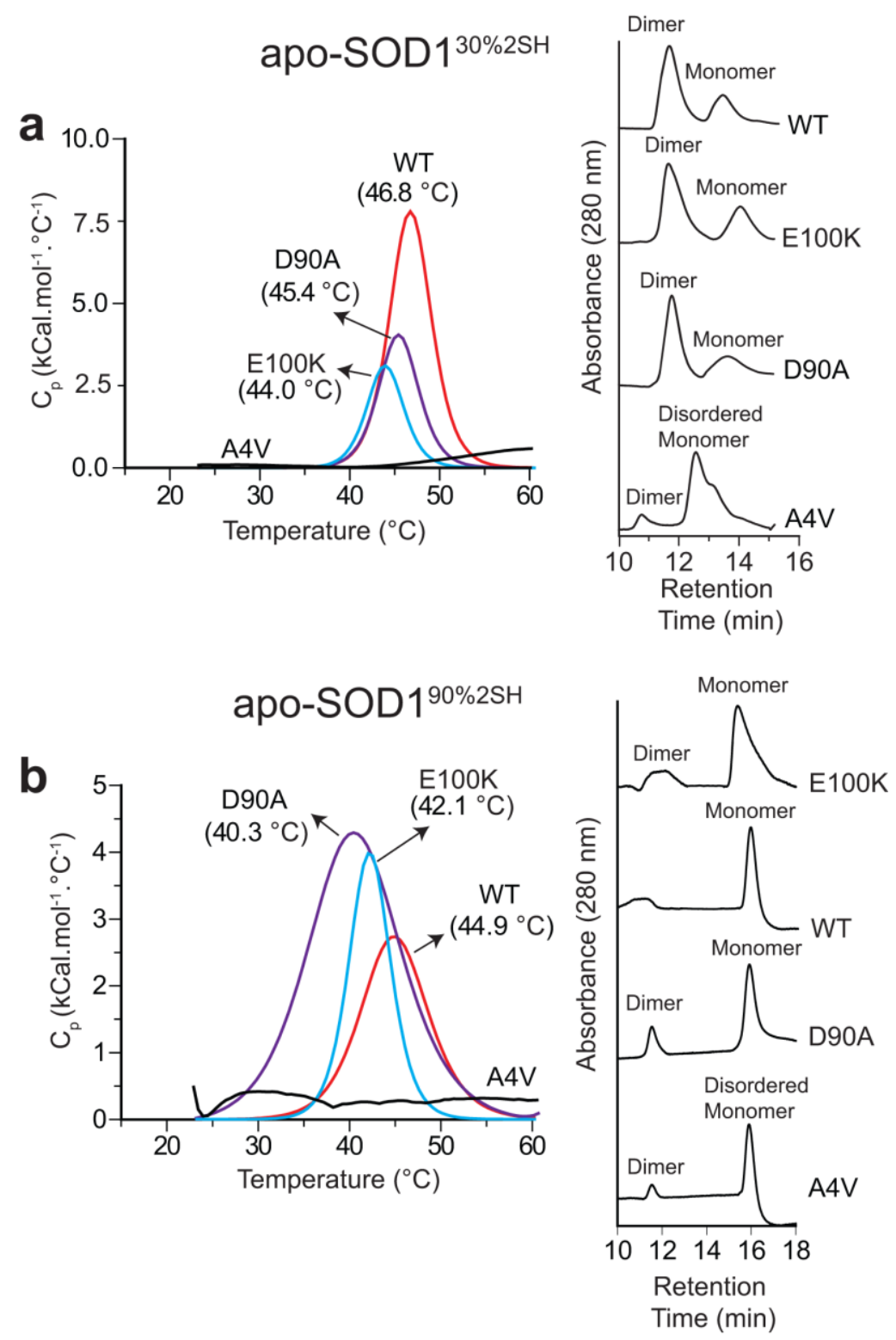

Figure S1. DSC thermograms and size-exclusion chromatograms of (a) apo-SOD1 ${ }^{30 \% 2 \mathrm{SH}}$ and (b) apo-SOD $1^{90 \% 2 \mathrm{SH}}$ after incubation in 10 and $100 \mathrm{mM}$ TCEP for $6 \mathrm{hr}$, respectively. A4V did not exhibit a thermogram (flat line) because of its disordered state. ${ }^{2}$ Percents reduction was calculated based on area under curve (AUC) ratio of size-exclusion chromatograms for dimeric and monomeric apo-SOD1. 


\section{Apo-SOD130\%2SH}
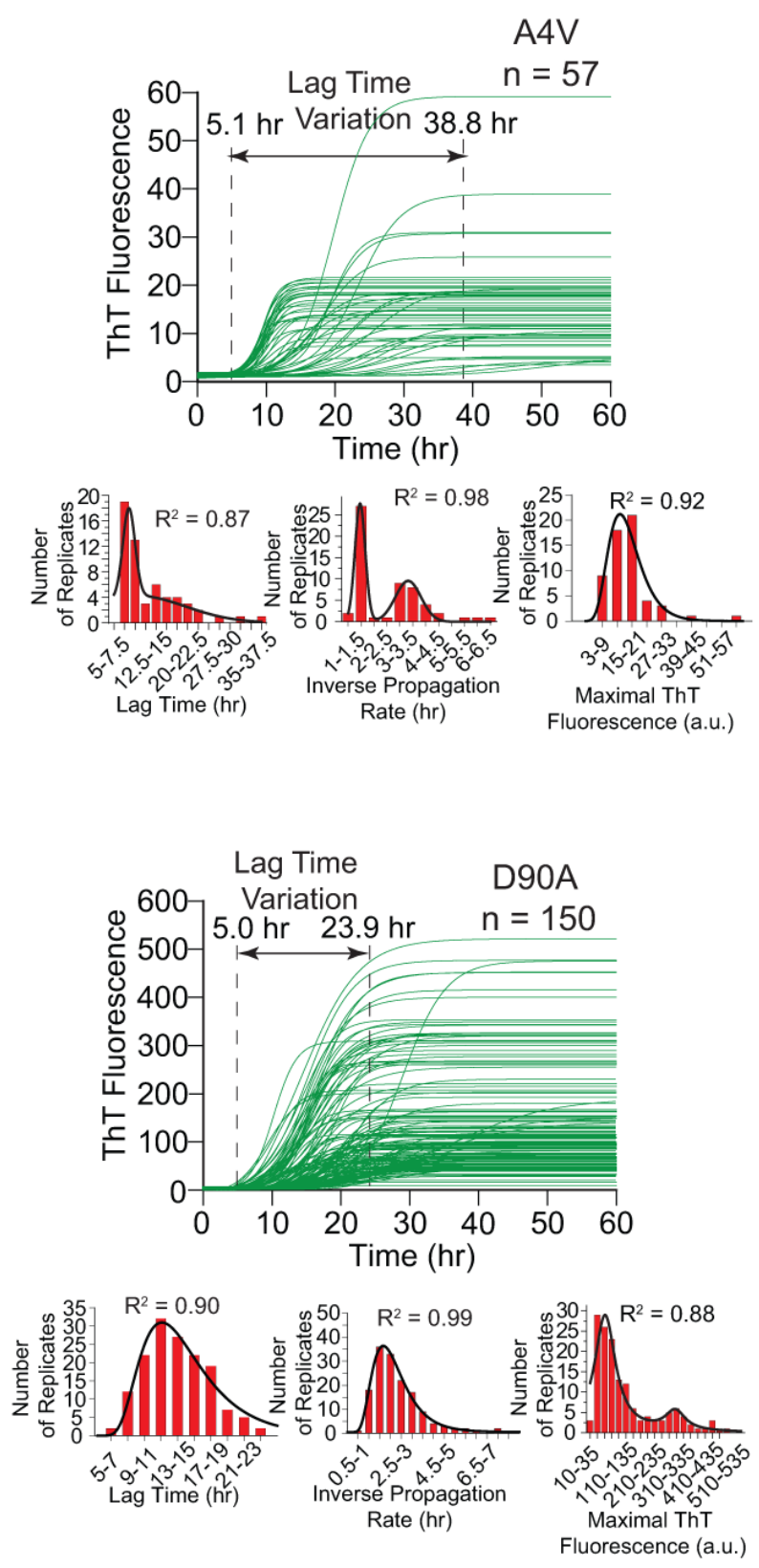

Figure S2. Sigmoidal fits of ThT fluorescence of replicate assays of A4V and D90A apoSOD $1^{30 \% 2 \mathrm{SH}}$. Histograms of iterate lag time, inverse propagation rate, and maximal ThT fluorescence are shown as insets below each plot. 


\section{Apo-SOD190\%2SH}
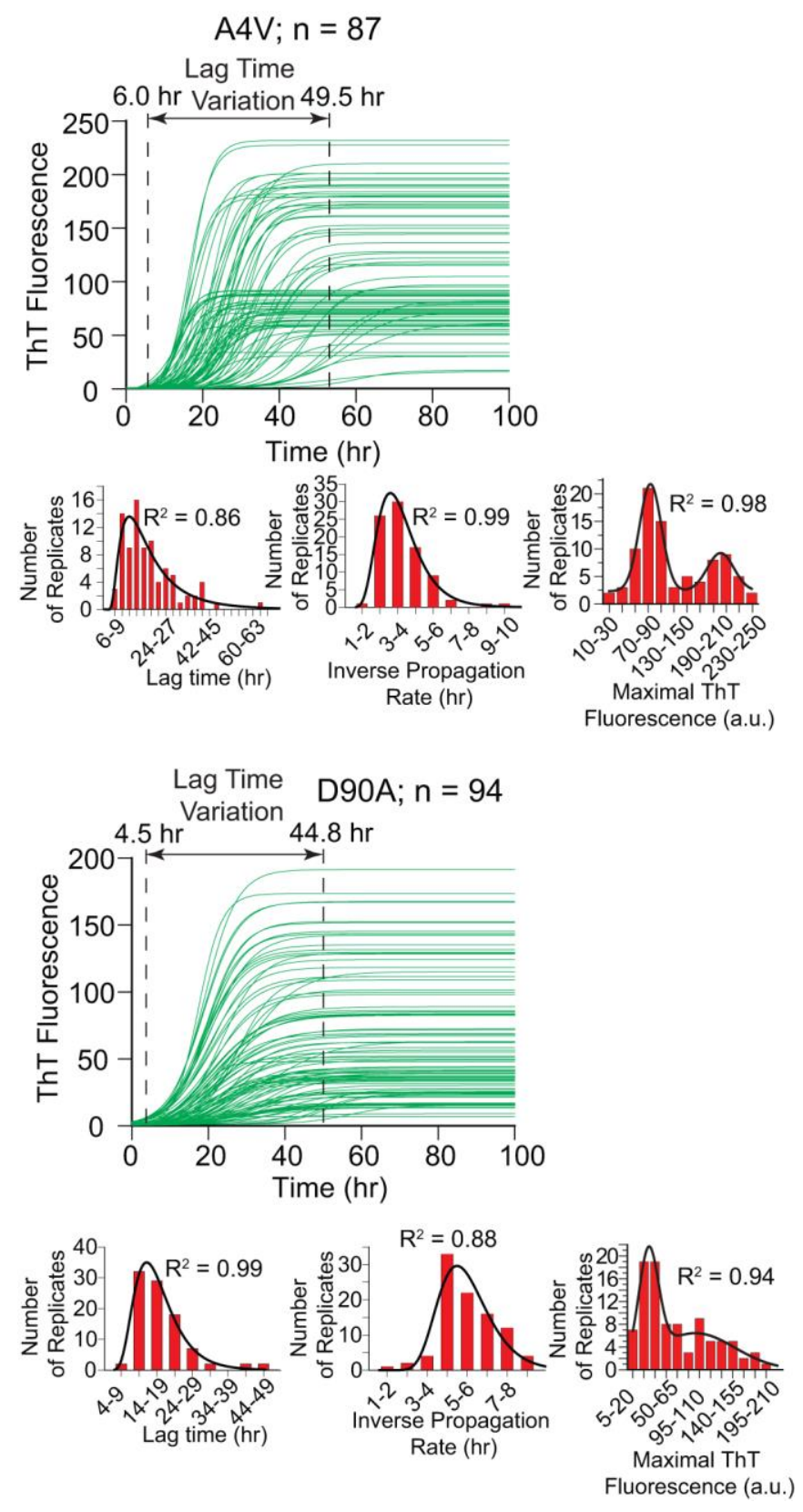

Figure S3. Sigmoidal fits of ThT fluorescence of replicate assays of A4V and D90A apoSOD $1^{90 \% 2 \mathrm{SH}}$. Histograms of iterate lag time, inverse propagation rate, and maximal ThT fluorescence are shown as insets below each plot. 

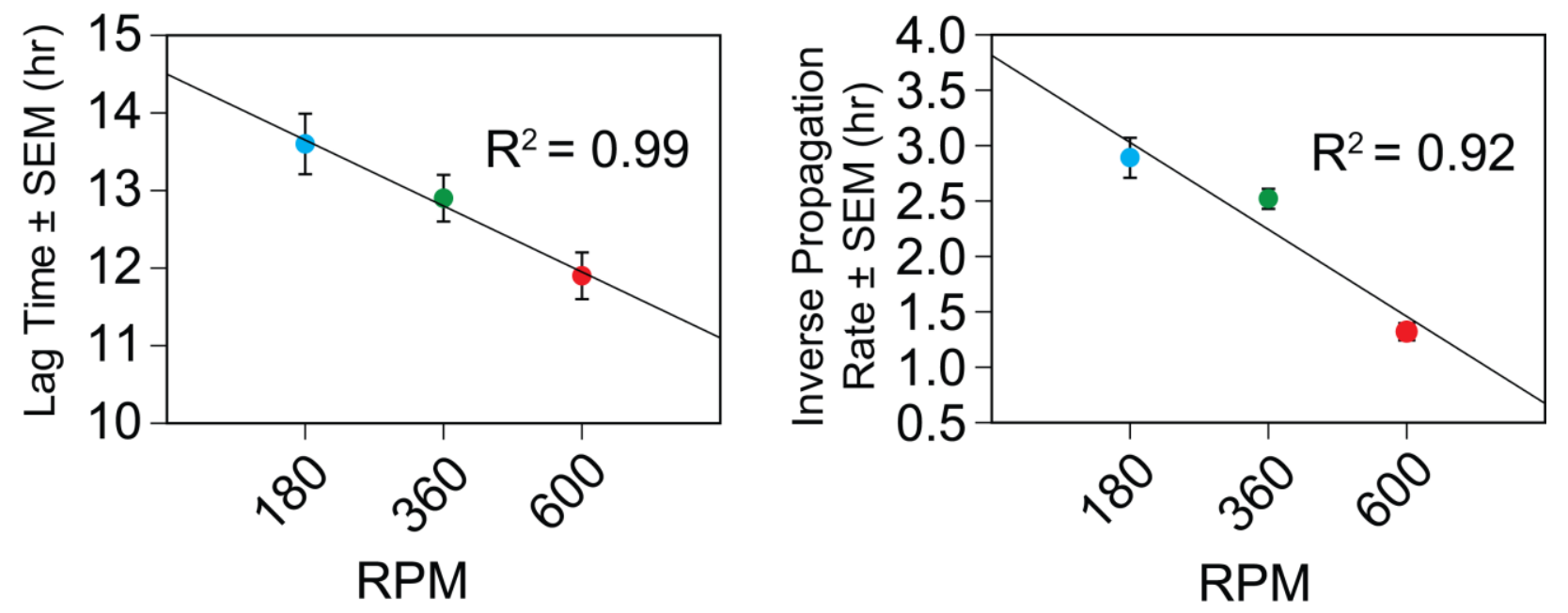

Figure S4. Average rate of nucleation and propagation of D90A apo-SOD1 ${ }^{30 \% 2 \mathrm{SH}}$ decreases linearly with increasing gyration speed. 

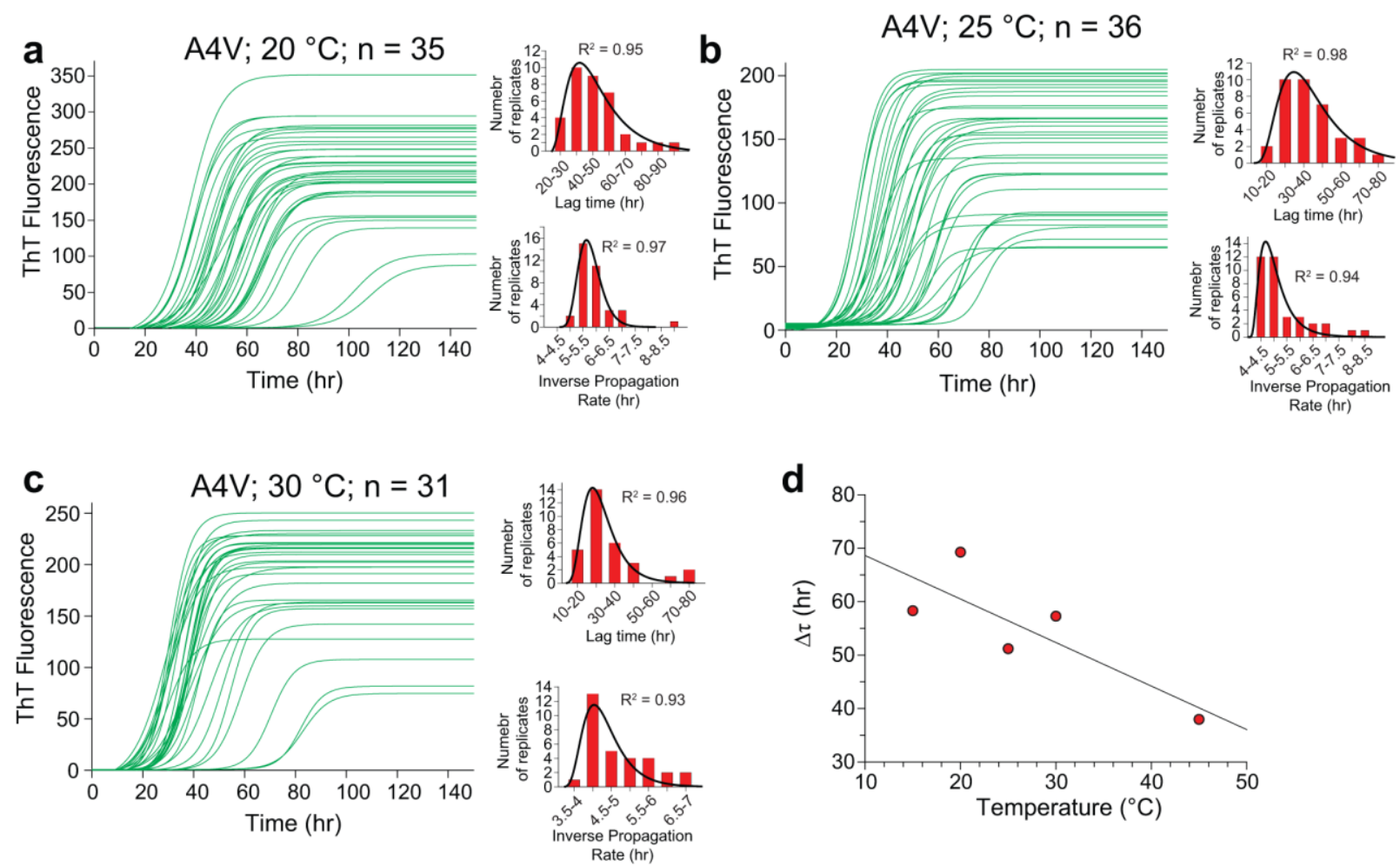

Figure S5. Fit traces of all replicates of ThT aggregation assays for A4V apo-SOD ${ }^{90 \% 2 \mathrm{SH}}$ in 100 $\mathrm{mM}$ TCEP at (a) $\mathrm{T}=20^{\circ} \mathrm{C}$, (b) $25^{\circ} \mathrm{C}$, and (c) $30^{\circ} \mathrm{C}\left(\mathrm{n}_{\text {total }}=102\right)$. Insets show the histograms of lag time and inverse propagation rate in each temperature. (d) Temperature-dependent range of lag time $(\Delta \tau)$, i.e., the difference between maximum and minimum lag times (outlier replicates) in a single kinetic assay of $\mathrm{A} 4 \mathrm{~V}$ apo-SOD1 $1^{90 \% 2 \mathrm{SH}}$. Histograms in (a-c) were fit with a 3 parameter log-normal function (Equation S2a). 

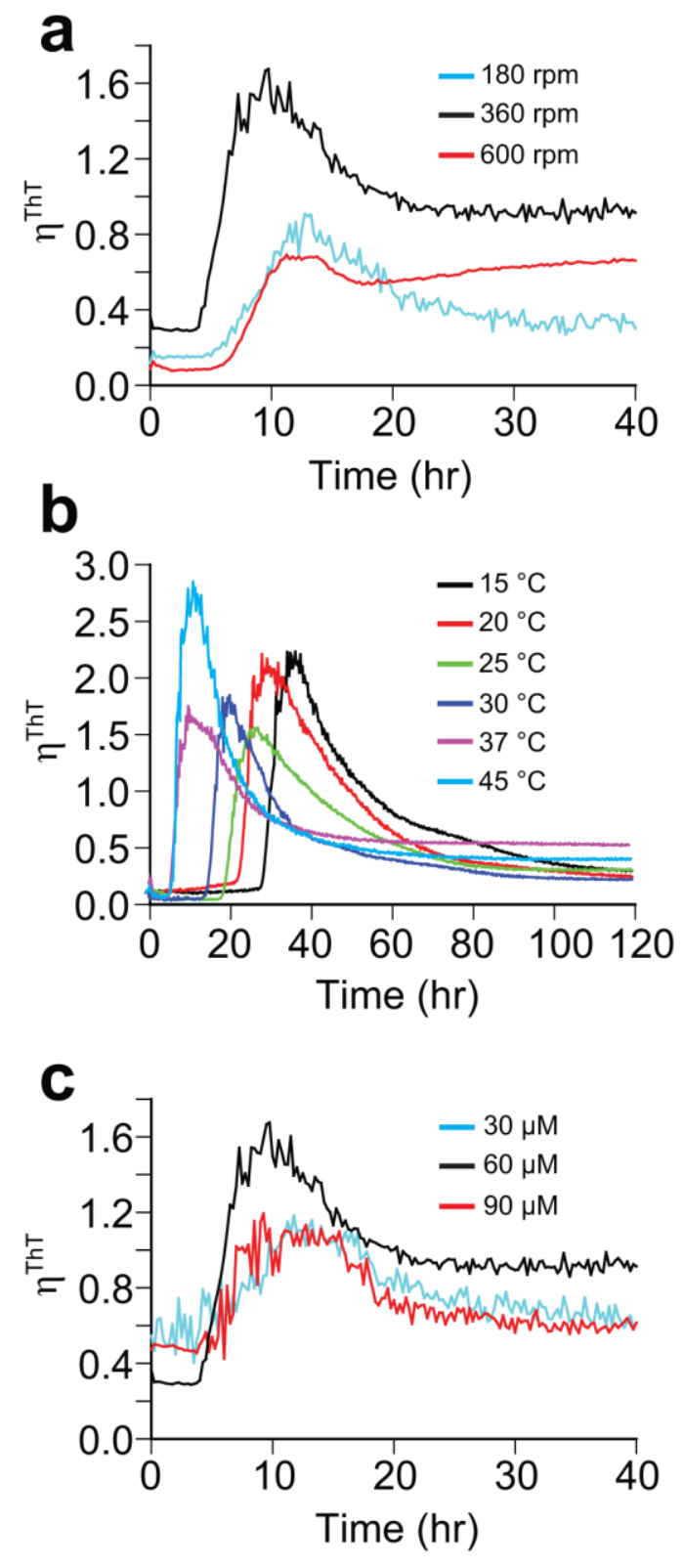

Figure S6. Noise plots of (a) D90A apo-SOD1 ${ }^{30 \% 2 \mathrm{SH}}$ during ThT assays at different shaking speeds, (b) ThT assays of A4V apo-SOD $1^{90 \% 2 \mathrm{SH}}$ at different temperatures, and (c) ThT assays of D90A apo-SOD1 ${ }^{30 \% 2 \mathrm{SH}}$ at different monomer concentrations. 


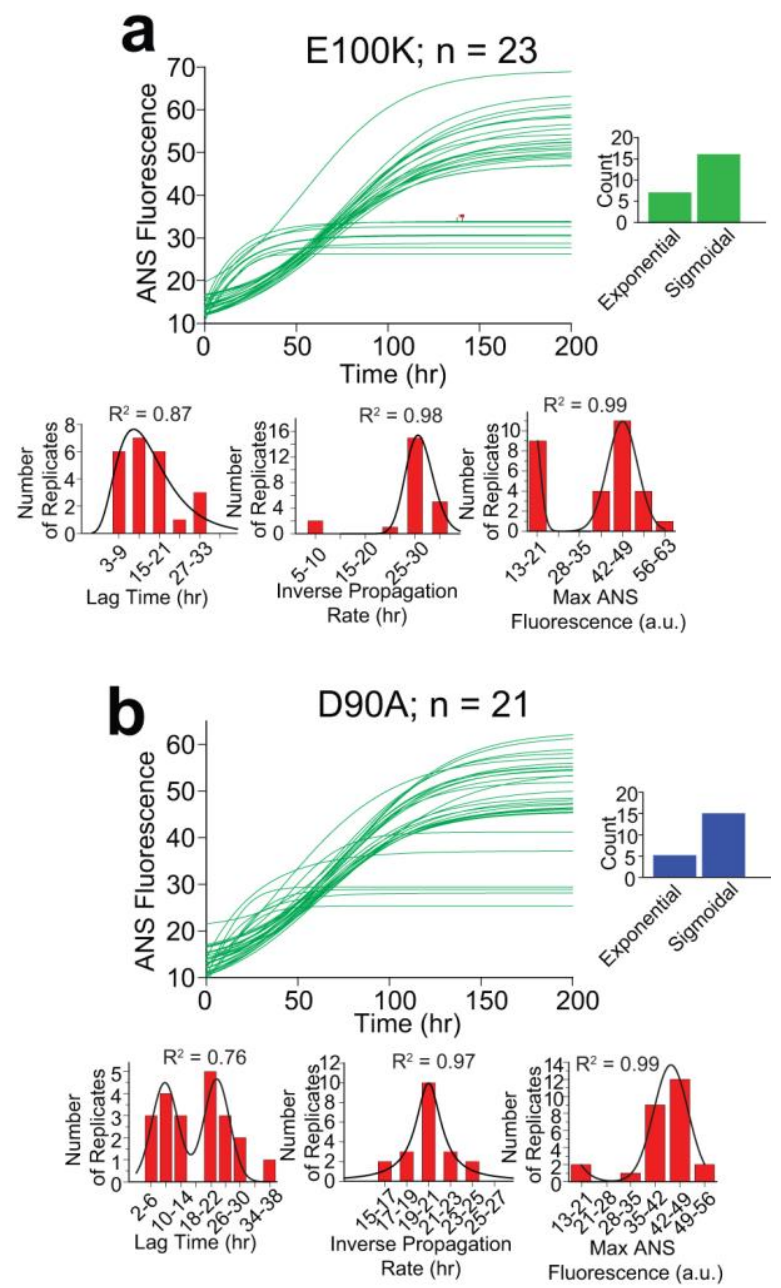

Figure S7. Plots of ANS fluorescence for (a) E100K, and (b) D90A apo-SOD1 ${ }^{90 \% 2 \mathrm{SH}}\left(\mathrm{n}_{\text {total }}=\right.$ 44). Insets below each plot illustrate the histograms for lag time and inverse propagation rate. Inset next to each plot shows the comparison between the number of exponential and sigmoidal traces. 


\section{Apo-SOD190\%2SH \\ $n_{\text {total }}=33$ for each protein \\ (only 3 are shown)}
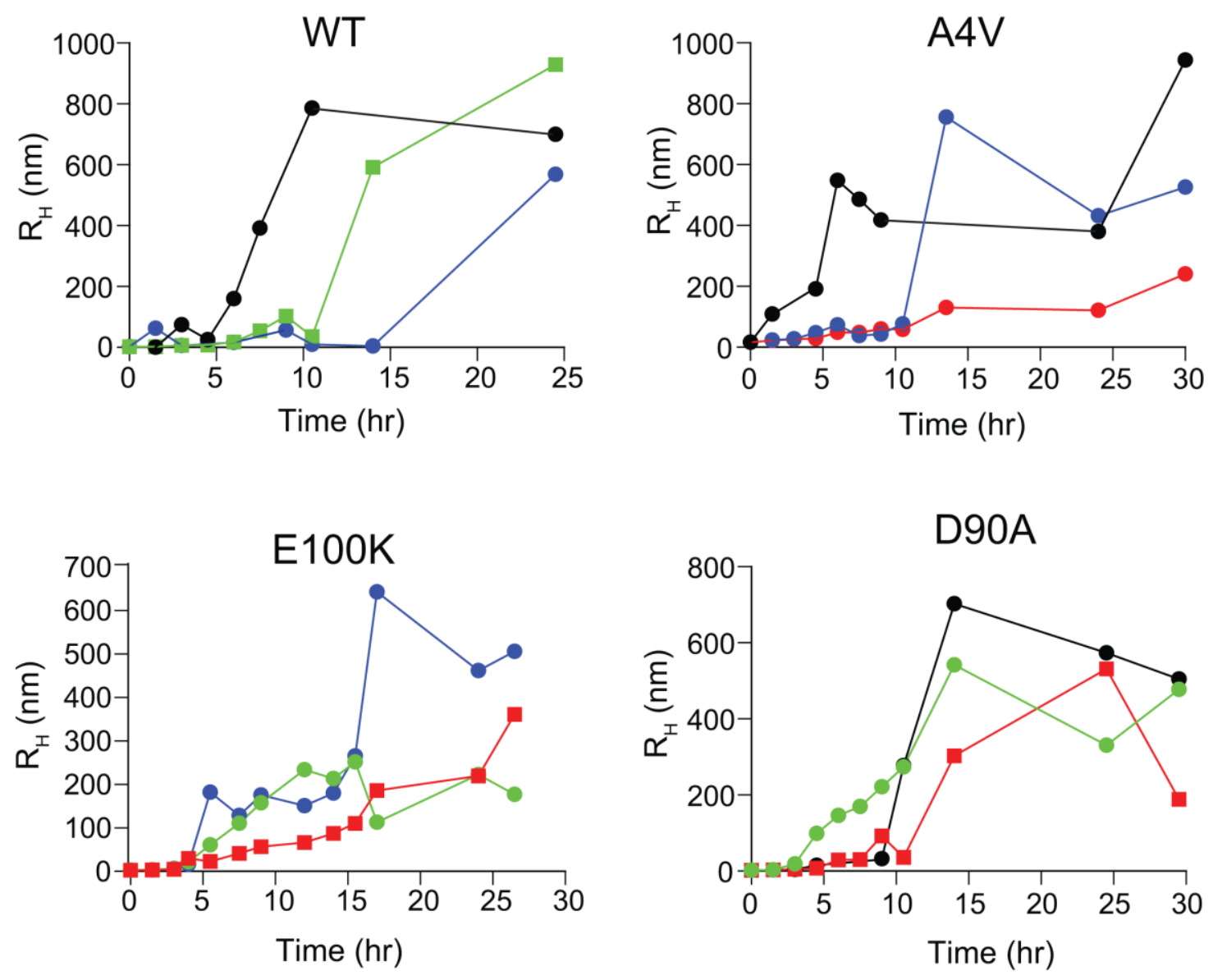

Figure S8. Selected replicate aggregation assays (as measured by DLS) for WT and three ALSvariant apo-SOD1 ${ }^{90 \% 2 \mathrm{SH}}$ proteins show a high degree of stochasticity among different replicates. $\mathrm{R}_{\mathrm{H}}=$ hydrodynamic radius of all species in solution (including monomeric SOD1). 


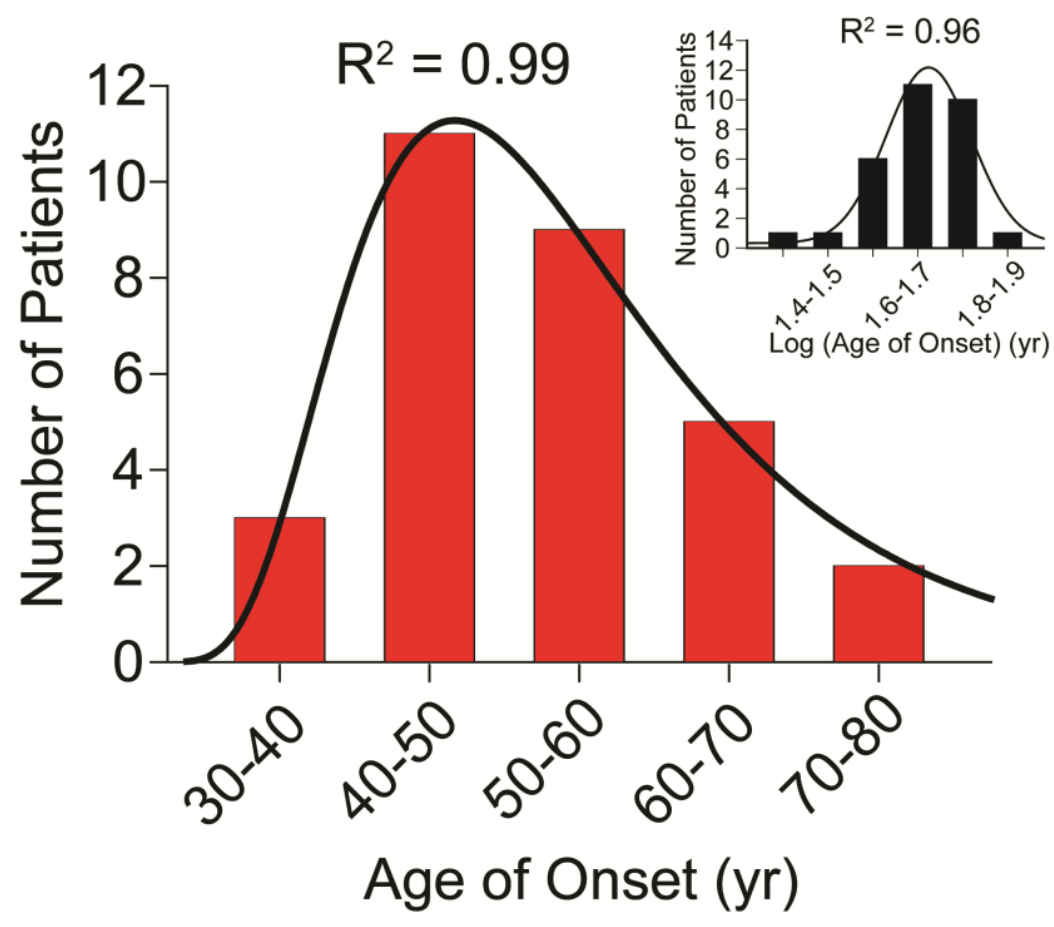

Figure S9. Histogram of age of disease onset for ALS patients with L144F SOD1 mutation $(\mathrm{n}=$ 30) shows a log-normal distribution (fit with a 3-parameter log-normal function, Equation S2a). Inset shows the normal distribution of logarithm of age of disease onset data, which mathematically confirms the authenticity of observed log-normal behavior. Data for age of disease onset were taken from Abel et al. ${ }^{3}$

Table S1. Metal content of WT and ALS-variant apo-SOD1 proteins before initiating the aggregation assay measured with ICP-MS.

\begin{tabular}{|c|c|c|}
\hline apo-SOD1 & $\mathrm{Zn}^{2+}$ (per monomer) & $\mathrm{Cu}^{2+}$ (per monomer) \\
\hline WT & 0.08 & 0.04 \\
\hline A4V & 0.03 & 0.01 \\
\hline D90A & 0.07 & 0.03 \\
\hline E100K & 0.08 & 0.05 \\
\hline
\end{tabular}


Table S2. Kinetic parameters of fibrillization of WT and ALS-variant apo-SOD1 $1^{30 \% 2 \mathrm{SH}}$ and apo$\mathrm{SOD} 1^{90 \% 2 \mathrm{SH}}$ in $150 \mathrm{mM} \mathrm{NaCl}$. Data are shown as mean \pm SEM. Average $\mathrm{R}^{2}$ of sigmoidal fits for all replicate assays was 0.98 .

\begin{tabular}{|c|c|c|c|c|c|c|}
\hline \multirow{2}{*}{$\begin{array}{c}\text { SOD1 } \\
\text { Variant }\end{array}$} & \multicolumn{3}{|c|}{$\begin{array}{c}\text { apo-SOD1 } \\
\left(\mathrm{n}_{\text {total }}=410\right)\end{array}$} & $\begin{array}{c}\text { apo-SOD1 } \\
(\tau)(\mathrm{hr}) \\
\left(\mathrm{n}_{\text {total }}=345\right)\end{array}$ \\
\cline { 2 - 7 } WT & $\begin{array}{c}12.9 \pm 0.4 \\
(\mathrm{n}=88)\end{array}$ & $2.4 \pm 0.1$ & $30.7 \pm 2.6$ & $\begin{array}{c}13.4 \pm 0.9 \\
(\mathrm{n}=89)\end{array}$ & $5.6 \pm 0.2$ & $45.3 \pm 3.6$ \\
\hline A4V & $\begin{array}{c}12.35 \pm 0.9 \\
(\mathrm{n}=57)\end{array}$ & $2.3 \pm 0.2$ & $13.7 \pm 1.2$ & $\begin{array}{c}19.8 \pm 1.1 \\
(\mathrm{n}=87)\end{array}$ & $3.8 \pm 0.1$ & $110.7 \pm 6.1$ \\
\hline E100K & $\begin{array}{c}11.2 \pm 0.5 \\
(\mathrm{n}=107)\end{array}$ & $1.7 \pm 0.1$ & $177.5 \pm 11.9$ & $\begin{array}{c}20.8 \pm 1.3 \\
(\mathrm{n}=75)\end{array}$ & $7.3 \pm 0.2$ & $44.6 \pm 3.9$ \\
\hline D90A & $\begin{array}{c}12.8 \pm 0.3 \\
(\mathrm{n}=150)\end{array}$ & $2.5 \pm 0.1$ & $139.4 \pm 9.5$ & $\begin{array}{c}13.9 \pm 0.8 \\
(\mathrm{n}=94)\end{array}$ & $5.9 \pm 0.1$ & $65.9 \pm 4.9$ \\
\hline
\end{tabular}


Table S3. Kinetic parameters of aggregation of WT and ALS-variant apo-SOD $1^{90 \% 2 S H}$ in 150 $\mathrm{mM} \mathrm{NaCl}$ measured with ANS fluorescence. Data are shown as mean $\pm \mathrm{SEM}$.

\begin{tabular}{|c|c|c|c|c|c|}
\hline \multirow{2}{*}{$\begin{array}{c}\text { SOD1 } \\
\text { Variant }\end{array}$} & \multicolumn{3}{|c|}{$\begin{array}{l}\text { Sigmoidal }^{\mathrm{a}} \\
\left(\mathrm{n}_{\text {total }}=71\right)\end{array}$} & \multicolumn{2}{|c|}{$\begin{array}{c}\text { Exponential }^{\mathrm{a}} \\
\left(\mathrm{n}_{\text {total }}=21\right)\end{array}$} \\
\hline & $\begin{array}{c}\text { Lag time, }(\tau) \\
(\mathrm{hr})\end{array}$ & $1 / k,(\mathrm{hr})$ & $f$, (a.u.) & $\begin{array}{c}\varphi^{\mathrm{b}} \\
(\mathrm{hr})\end{array}$ & $\begin{array}{c}\delta^{\mathrm{b}} \\
(\mathrm{hr})\end{array}$ \\
\hline WT & $\begin{array}{c}12.6 \pm 2.0 \\
(\mathrm{n}=18)\end{array}$ & $25.9 \pm 1.3$ & $40.4 \pm 1.7$ & $\begin{array}{c}15.8 \pm 0.6 \\
(\mathrm{n}=3)\end{array}$ & $0.072 \pm 0.003$ \\
\hline A4V & $\begin{array}{c}18.7 \pm 1.7 \\
(n=20)\end{array}$ & $19.4 \pm 1.6$ & $27.1 \pm 2.2$ & $\begin{array}{c}9.8 \pm 1.0 \\
(\mathrm{n}=7)\end{array}$ & $0.070 \pm 0.007$ \\
\hline E100K & $\begin{array}{c}12.2 \pm 1.6 \\
(\mathrm{n}=17)\end{array}$ & $26.4 \pm 1.4$ & $40.4 \pm 2.4$ & $\begin{array}{c}18.7 \pm 0.7 \\
(n=6)\end{array}$ & $0.049 \pm 0.004$ \\
\hline D90A & $\begin{array}{c}14.4 \pm 2.0 \\
(n=16)\end{array}$ & $26.5 \pm 0.7$ & $41.3 \pm 0.9$ & $\begin{array}{c}20.6 \pm 1.2 \\
(\mathrm{n}=5)\end{array}$ & $0.047 \pm 0.005$ \\
\hline
\end{tabular}

${ }^{\mathrm{a}}$ Average $\mathrm{R}^{2}$ of sigmoidal fits for all replicate assays was 0.99 .

${ }^{b}$ Exponential plots were fit with an exponential growth function using Equation S4.

\section{Supporting References:}

1. Abdolvahabi, A., Shi, Y., Rhodes, N. R., Cook, N. P., Marti, A. A., Shaw, B. F. (2015) Arresting Amyloid with Coulomb's Law: Acetylation of ALS-Linked SOD1 by Aspirin Impedes Aggregation. Biophys. J. 108, 1199-1212.

2. Shaw, B. F., Durazo, A., Nersissian, A. M., Whitelegge, J. P., Faull, K. F., Valentine, J. S. (2006) Local unfolding in a destabilized, pathogenic variant of superoxide dismutase 1 observed with H/D exchange and mass spectrometry. J. Biol. Chem. 281, 18167-18176.

3. Abel, O., Shatunov, A., Jones, A. R., Andersen, P. M., Powell, J. F., Al-Chalabi, A. (2013) Development of a Smartphone App for a Genetics Website: The Amyotrophic Lateral Sclerosis Online Genetics Database (ALSoD). JMIR Mhealth. Uhealth. 1, e18. 